\title{
Prazer e Dor na Docência: revisão bibliográfica sobre a Síndrome de Burnout
}

\section{Pleasure and Pain in the Faculty: bibliographical revision on Syndrome of Burnout}

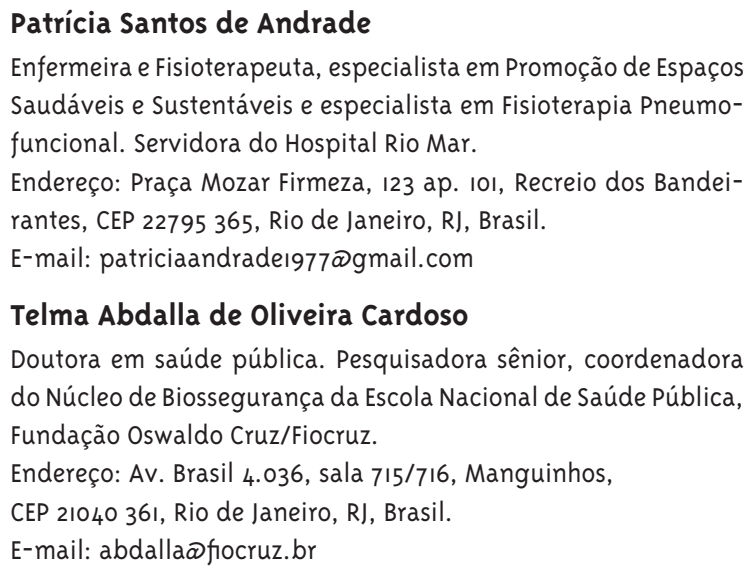

E-mail: abdallaœfiocruz.br

\section{Resumo}

Os transtornos mentais, atualmente, são os principais responsáveis pelo afastamento do trabalho por longos períodos de tempo. São eles que conferem riscos para a manutenção da saúde mental, através do comportamento e da emoção. Burnout é o resultado ao estresse crônico, incrementado na interação com outras pessoas. Esta pesquisa objetiva apresentar algumas reflexões acerca dos principais fatores de risco para o desenvolvimento da Síndrome de Burnout entre os docentes, a fim de compreendê-los dentro de um processo de desgaste físico-emocional em decorrência do trabalho. Para tanto, realizou-se uma revisão bibliográfica, de natureza qualitativa, na base de dados da Biblioteca Virtual em Saúde (BVS/ BIREME), de artigos sobre a temática em questão. Os resultados deste estudo demonstram a carência de pesquisas nessa área. É necessário aprofundar o conhecimento sobre a manifestação do estresse ocupacional entre os docentes, a fim de se compreender e elucidar alguns problemas enfrentados por essa atividade, como a insatisfação profissional, o baixo rendimento no trabalho, o absenteísmo e algumas doenças ocupacionais, dentre elas o Burnout.

Palavras-chave: Burnout; Estresse ocupacional; Professores; Saúde ocupacional. 


\section{Abstract}

Today, the mental disorders are mainly responsible ones for the absence from work for long periods of time. They are who confer risks for the maintenance of the mental health, through the behavior and of the emotion. Burnout is a reply of one stress chronic, caused by the interaction with other people. This research aims to present some reflections on the main risk factors for the development of Syndrome of Burnout between teachers, in order to understand them within a physical and emotional wear as a result of the work. For such, a bibliographic search, of qualitative nature, was made in the Virtual Health Library (BVS/BIREME), articles on the topic in question. The results of this study demonstrate the lack of research in this area. It is necessaryto increase knowledge about the manifestation occupational stress between teachers, in order to understand and elucidate some problems faced by this activity, such as dissatisfaction, low work performance, absenteeism and some occupational diseases, among them Burnout.

Keywords: Burnout; Professional Stress; Teachers; Occupational Health.

\section{Introdução}

O trabalho tem um sentido fundamental na estruturação da identidade do indivíduo. É através dele que as pessoas têm a possibilidade de realização, de expressão de competências e de integração social.

Diante dos impactos causados pelas mudanças de valores do mundo, moderno e globalizado, do processo de reestruturação produtiva, iniciado nos anos 9o, o perfil do trabalho e dos trabalhadores modificou-se para adaptar-se às inovações tecnológicas com os novos modelos gerenciais de qualidade estabelecidos. Juntamente com isso houve uma intensificação do trabalho, decorrente do aumento no ritmo, das responsabilidades e da complexidade das tarefas, trazendo também o aumento do desemprego, do trabalho informal, mudanças nas formas de trabalho e dos determinantes do processo saúde-doença.

A Organização Mundial da Saúde (OMS) afirma que o estresse é uma epidemia global, em que o homem contemporâneo vivencia enormes exigências de atualização e é chamado constantemente a lidar com novas informações. O ser humano cada vez mais se vê diante de responsabilidades, obrigações, autocrítica, dificuldades fisiológicas e psicológicas (Selye, 1965), além de inúmeras situações às quais precisa adaptar-se, como por exemplo, diante de demandas e pressões externas vindas da família, do meio social, do trabalho/escola e/ou do ambiente.

Os trabalhadores estão sujeitos a condições de trabalho que podem gerar sofrimento, tensão emocional, insatisfação, irritação, insônia, envelhecimento prematuro, aumento do adoecimento e morte por doenças cardiovasculares e outras doenças crônico-degenerativas como as osteomusculares. Atualmente, há registros de morte súbita por excesso de trabalho. Identificam-se, ainda, os sintomas psíquicos como a síndrome da fadiga crônica, o estresse, a Síndrome de Burnout e outros distúrbios inespecíficos e ainda pouco conhecidos (Franco, 2003; Dias, 2000).

Estudos mostram que esse desequilíbrio na saúde do trabalhador pode acarretar o aumento nos índices de absenteísmo, gerando licenças médicas e a necessidade por parte da organização, de reposição de funcionários, transferências, novas contratações, novos treinamentos, entre outras despesas. A qua- 
lidade dos serviços prestados e o nível de produção fatalmente serão afetados, assim como a lucratividade (Moreno-Jiménez, 200o; Schaufeli, 1999).

As doenças relacionadas ao trabalho são consideradas, pela OMS, como multifatoriais, tendo, por conseguinte multi causas, inclusive de fatores físicos, organizacionais, individuais e socioculturais (Sousa, 2005).

As interações entre ambiente de trabalho, gestão e processo de trabalho, bem como as variáveis de natureza não física relativas ao indivíduo, como personalidade, estilo de vida e apoio social, e, ainda, a vulnerabilidade e a resistência ao estresse, que contribuem para as percepções e experiências da atividade laboral, atuam sobre a saúde e/ou desempenho do trabalhador (Brandão Junior, 2003; Fernandes, 1999).

No Brasil, dados do Instituto Nacional do Seguro Social (INSS) mostram que os transtornos mentais ocupam o terceiro lugar entre as causas de benefícios previdenciários de auxílio-doença, por incapacidade temporária ou definitiva para o trabalho (Brasil, 2002).

E apesar de não existirem estudos estatísticos suficientes que possam evidenciar esta realidade brasileira, a precarização das condições de trabalho, a diversidade de processos produtivos, a instabilidade econômica e social e o elevado desemprego nos alertam de que a incidência de doença psíquica vinculada ao trabalho não deve ser muito divergente do que é experimentado naqueles países, tornando a situação de vida e saúde do trabalhador brasileiro ainda mais crítica (Sousa, 2005, p.17).

A doença raramente é bem-vista no trabalho, pois os valores nesse ambiente são construídos, principalmente, sob o foco da produtividade. Estar doente significa comprometer os resultados e a imagem da empresa (França, 1999).

O trabalho com a doença e o sofrimento frequentemente são causas de estresse físico e psicológico, levando o profissional ao estresse ocupacional.

O estresse é um dos problemas mais comuns que o ser humano enfrenta, caracterizado por um estado de tensão, ocasionando um desequilíbrio intenso no organismo, que pode desencadear diversas doenças graves (Lipp, 2001).
O estresse ocupacional pode ser entendido como o resultado de relações complexas entre condições de trabalho, condições externas ao trabalho e características do trabalhador, nas quais a demanda das atividades excede as habilidades do trabalhador para enfrentá-las (Murphy,1984). O indivíduo começa a perceber seu ambiente de trabalho como ameaçador, quando sua necessidade de realização pessoal e profissional, e/ou sua saúde física ou mental, prejudicam a interação desta com o trabalho e que este ambiente tenha demandas excessivas a ele, ou que ele não contenha recursos adequados para enfrentar tais situações (França e Rodrigues, 1997). Neste contexto, ocorre um desgaste anormal e/ou uma diminuição da capacidade do organismo para o trabalho.

A escola, como qualquer ambiente laboral, também sofreu a massificação da sociedade industrial moderna, cobrando dos docentes parâmetros de produtividade e eficiência empresarial (Frigotto, 1999). Neste contexto, os professores, como trabalhadores, passaram a preocupar-se não só com suas funções docentes, mas também com questões baseadas no paradigma da civilização industrial, isto é, com sua carreira, sua segurança e seu salário (Carlotto, 2002a). Esses profissionais passam a ter, além dessa sobrecarga, um tempo reduzido para a sua qualificação, comprometendo seu desenvolvimento e realização profissional. Frente a essas questões, fica evidente que na natureza do trabalho do docente existem diversos estressores que, se persistentes, podem levar à Síndrome de Burnout.

Este estudo tem como objetivo apresentar considerações acerca dos principais fatores de risco para o desenvolvimento da Síndrome de Burnout entre os docentes, através da fundamentação teórica baseada na literatura, a fim de compreendê-los dentro de um processo de desgaste físico-emocional em decorrência da competitividade da sociedade contemporânea.

A trajetória metodológica escolhida para o desenvolvimento desta contribuição foi a pesquisa bibliográfica de natureza qualitativa, mediante busca eletrônica, na base de dados da Biblioteca Virtual em Saúde (BVS/BIREME), de artigos sobre a temática estudada. Na BVS foram consultadas as seguintes bases de dados: Literatura Latino-Americana e do 
Caribe em Ciências da Saúde (LILACS), Literatura Internacional em Ciências da Saúde (MEDLINE) e Scientific Eletronic Library Online (SCIELO).

A escolha das bases de dados deve-se ao fato de conterem o maior número de periódicos indexados na área da saúde, disponibilizados eletronicamente, o que possibilitou uma visão mais ampla das pesquisas realizadas.

Como localizadores dos artigos, foram utilizados os descritores empregados pelos Descritores em Ciências da Saúde (DECS) da BVS que tivessem uma relação mais próxima com a temática a ser estudada. Foram eles: estresse; condições de trabalho, esgotamento profissional; docentes e saúde do trabalhador.

Foram ainda utilizados como critérios de inclusão: artigos disponibilizados na íntegra; metodologia descrita com clareza e referência aos fatores que contribuem para o aparecimento da Síndrome de Burnout em docentes.

\section{Os Transtornos Mentais e a Sindrome de Burnout}

Os transtornos mentais são atualmente os principais responsáveis pelo afastamento do trabalho por longos períodos (Mendes, 1995). São eles que conferem riscos para a manutenção da saúde mental, através do comportamento e da emoção.

0 estresse no trabalho, a vulnerabilidade ao estresse, a não satisfação com o trabalho, a fadiga crônica, a ansiedade, parecem fazer-se acompanhar de um desconforto emocional significativo e podem aumentar a probabilidade de o indivíduo desenvolver problemas de comportamento.

Seligmann-Silva (1986) ressalta as agressões dirigidas à mente pela vida laboral dos trabalhadores. Elas são confrontadas pelas fontes de vitalidade e saúde, representadas pelas resistências de natureza múltipla, individuais e coletivas, que funcionam como preservadoras da identidade, dos valores e da dignidade desses profissionais. A saúde mental pode ser caracterizada pelo equilíbrio desses fatores e quando há a quebra nesse equilíbrio há a geração de transtornos (Glina e col., 2001).

Segundo Codo (1999), o estresse prolongado pode ou não levar a um desgaste geral do organismo, depen- dendo da sua intensidade, duração, vulnerabilidade do indivíduo afetado e sua habilidade em administrálo. Assim o estresse laboral ocorre de forma particularizada para os trabalhadores dos diferentes setores, pois cada indivíduo reage de forma particular aos eventos estressores (Araújo e col., 2005). Este enfrentamento são formas cognitivas, comportamentais e emocionais como os indivíduos administram situações estressantes São tentativas de preservação da saúde mental e física dos indivíduos afetados. É um processo dinâmico e não uma única reação faz parte de uma série de respostas que envolvem a interação do indivíduo com seu ambiente (Straub, 2005).

Nessa linha de pensamento, alguns autores consideram o estresse como um fenômeno complexo, que não aparece repentinamente. É um processo gradual de resposta a experiências e acontecimentos vividos (Silva, 200o). Quando não se consegue lidar com essa tensão emocional, o corpo e a mente mostram sinais de alerta: sensação de desgaste físico e mental, falhas de memória, questionamentos sobre a própria competência, apatia e desinteresse por coisas que antes davam prazer (Lipp, 2004).

O estresse é um processo caracterizado por um conjunto de reações - fisiológicas, psíquicas e até mesmo comportamentais - de adaptação que o organismo emite quando é exposto a qualquer estímulo, uma forma de adaptação para restabelecer o equilíbrio (Pafaro e Martino, 2004; Lipp, 200o). É uma reação de defesa e adaptação frente a um agente estressor. Alguns autores tratam o estresse como uma Síndrome evolutiva, que possui três fases (Lipp e Rocha, 2008; Selye,1965):

a) alarme, fase positiva, na qual o indivíduo está mais atento, produtivo e motivado; fase de orientação e identificação do perigo;

b) resistência, período de adaptação do corpo à nova situação; fase de alerta prolongado, em que existe maior vulnerabilidade aos agentes de risco; quaseexaustão oscila entre equilíbrio e desequilíbrio emocional com predisposição a desenvolver doenças físicas, como gastrite, hipertensão arterial, diabetes melito, dentre outras; e

c) exaustão, término da resistência, seja pelo desaparecimento do agressor/estressor, seja pelo cansaço dos mecanismos de resistência; fase patológica na qual há o desencadeamento ou a potencialização de 
doenças, devido ao comprometimento do sistema imunológico destes indivíduos, tornando-os mais susceptíveis.

O estresse, ao se tornar crônico, pode ter como resposta a Síndrome de Burnout. Costa e colaboradores (2003) afirmam que a fase de exaustão emocional é o que anuncia o primeiro sinal da Síndrome do Burnout, porém seu surgimento é progressivo e cumulativo, podendo levar até mesmo décadas para seu aparecimento (Castro e Zanelli, 2007; Rudow, 1999; França, 1987).

A expressão inglesa Burnout designa aquilo que deixou de funcionar por exaustão de energia, esgotamento físico, psíquico e emocional, em decorrência da má adaptação do indivíduo a um trabalho altamente estressante e com grande carga tensional. O termo foi utilizado inicialmente por Brandley em 1969, mas tornou-se conhecido a partir dos artigos de Freudenberger de 1974, 1975 e 1979. Freudenberger associou o termo à estafa por estresse crônico (Maslach e Jackson, 1981).

[...] estado de fadiga ou frustração causado pela dedicação excessiva e prolongada a uma causa. Pode ocorrer também pelo fato de a pessoa persistir na tentativa de alcançar uma meta ou preencher uma expectativa que é realisticamente impossível de conseguir naquele momento. Quanto mais se tenta, tanto mais o desgaste vai se desenvolvendo. Neste caso, o inevitável será um esvaziamento dos recursos do indivíduo, um desgaste de sua vitalidade, da energia e da habilidade de funcionamento (Frendenberger e Richelson, 1981 apud Lipp, 2001, p. 225)

Benevides-Pereira (2002) afirma que a Síndrome de Burnout vai além do estresse. É uma reação ao estresse ocupacional crônico, que está associado a uma Síndrome composta por comportamento de desilusão, exaustão e isolamento (Freudenberger, 1974). Afeta principalmente os trabalhadores em contato direto com outras pessoas.

A Síndrome de Burnout possui sinais como: ceticismo, insensibilidade, despreocupação, desconforto, ansiedade e até mesmo do sentimento de divisão que um indivíduo sente entre o que pode fazer e o que efetivamente consegue fazer com outras pessoas. Geralmente as pessoas acometidas apresentam: insônia, fadiga, irritabilidade, tristeza, desinteresse, apatia, angústia, tremores e inquietação; caracterizando uma síndrome depressiva ou de ansiedade (Maslach e Leiter, 2008; Codo, 1999). A associação de todos os sintomas preenche os critérios para o diagnóstico da Síndrome de Burnout (Mendes, 1995).

Na definição de Farber (1999), essa Síndrome é resultante do trabalho, que se origina da discrepância da percepção individual entre esforço e consequência. Ressalta, também, que a percepção é influenciada por fatores individuais, organizacionais e sociais; e envolve três elementos que podem estar associados, mas não são independentes: despersonalização, exaustão emocional e baixo envolvimento pessoal no trabalho. Quando não há possibilidade de afirmação da personalidade no trabalho há a ocorrência de processos de depressão e tensão nervosa permanente (Dejours, 1992; Friedmann, 1983).

A Síndrome de Burnout, assim como o estresse, o esgotamento, a falta de repouso e lazer e adversidades no modo de vida, ou seja, os transtornos mentais e do comportamento relacionados ao trabalho, foram classificados no Grupo V da Classificação Estatística Internacional de Doenças e Problemas Relacionados com a Saúde, reconhecida pela sigla CID (International Statistical Classification of Diseases and Related Health Problems/ICD). A CID é resultante do esforço da OMS no estabelecimento de uma classificação internacional de doenças relacionadas com a saúde. Em 1988, foi lançada a primeira CID, que é revisada periodicamente e encontra-se, desde 1992 na sua décima edição, por isso possui a denominação de CID-10, como é conhecida. A maioria dos países passou a adotá-la desde então. A Síndrome de Burnout é classificada no inciso XII, sob o código Z73 (Brasil, 2002).

No Brasil, desde maio de 1996, as regulamentações da Previdência Social, consideram a Síndrome de Burnout como um dos "agentes patogênicos causadores de doenças profissionais”, no grupo das doenças consideradas de etiologia múltipla.

Com esta caracterização, a execução do trabalho passou a ser um fator que contribui à ocorrência de acidentes, justificando a emissão da Comunicação de Acidente de Trabalho (CAT) (Ferenhof e Ferenhof, 2002; Benevides-Pereira, 2002; Brasil, 1999). 


\section{Sindrome de Burnout e os Docentes}

No Brasil, apesar dos avanços teóricos sobre as relações entre trabalho e saúde dos professores, a literatura científica ainda é muito carente. Entretanto, a partir da década de 1990, observou-se um aumento no número de publicações que exploram especialmente os efeitos do trabalho sobre a saúde mental, como o estresse e a Síndrome de Burnout (Codo e Vasques, 200ob).

Esses estudos demonstraram que os profissionais envolvidos em atividades onde há o contato direto com o público, como os profissionais da saúde e da educação, são mais vulneráveis à Síndrome de Burnout (Carlotto e Palazzo, 2006; Contaifer e col., 2003; Silva e Carlotto, 2003; Jimenez e col., 2002; Maslach e col., 2001; Codo e Vasques, 2000a; Maslach e Leiter, 1999; Schaufeli e col., 1993; Maslach, 1993). O trabalho de Schaufeli e colaboradores (1993), demonstrou que é a doença ocupacional mais frequente entre os profissionais da área de educação.

As manifestações de Burnout em professores são reações psicossomáticas e, segundo Rodrigues e Gasparini (1992), estas doenças são consequências da interação dos processos psicológicos e mentais e das funções somáticas e viscerais.

Neste sentido, os docentes formam uma categoria especialmente exposta aos riscos psicossociais. Farber (1999) destaca a baixa valorização dos professores como um fator importante para o desenvolvimento da Síndrome de Burnout. Essa valorização é consequência do próprio contexto ocupacional e da organização acadêmica e escolar, com situações nas quais se desequilibram as expectativas individuais do profissional e a realidade do trabalho diário. Entre elas estão a relação com os alunos e seu baixo nível de motivação; ou o tipo de jornada de trabalho; sobrecarga de atividade laboral, referente não só ao número de horas de dedicação, como também a outros elementos, como a proporção aluno/professor, o sistema de horários, o nível de envolvimento com os alunos; inadequação entre formação e desenvolvimento profissional; clima organizacional e a coordenação com as demandas da administração, da supervisão e da estrutura do local de trabalho; além da baixa remuneração salarial (Burke e col., 1996; Byrne, 1991; Manassero e col., 1995; Doménech, 1995; Friedman, 1991,1995; Crane e Iwanicki, 1986).

Nos últimos anos, outras questões se adicionaram às da organização do trabalho docente. As responsabilidades e exigências que recaem sobre os educadores têm aumentado consideravelmente, coincidindo com um processo histórico de uma rápida transformação do contexto social, o qual tem sido traduzido em uma modificação do papel do professor. Carlotto (2002a) aponta que as mudanças no papel do professores podem estar ligadas à:

[...] a) evolução e a transformação dos agentes tradicionais de socialização (família, ambiente cotidiano e grupos sociais organizados), que, nos últimos anos, vêm renunciando às responsabilidades que antigamente vinham desempenhando no âmbito educativo, passando a exigir que as instituições escolares assumam esta responsabilidade; b) o papel tradicionalmente designado às instituições escolares, com respeito à transmissão de conhecimentos, viu-se seriamente modificado pelo aparecimento de novos agentes de socialização (meios de comunicação e consumo cultural de massas, etc.), que se converteram em fontes paralelas de informação e cultura; e c) o conflito que se instaura nas instituições quando se pretende definir qual é a função do professor, que valores, dentre os vigentes em nossa sociedade, o professor deve transmitir e quais deve questionar (Carlotto, 2002a, p. 22).

Estas transformações trazem aos docentes um desafio pessoal, no sentido de responder às novas expectativas projetadas sobre eles, acarretando um desgaste físico-emocional, que são estressores e, se persistentes, podem levar ao desenvolvimento da Síndrome de Burnout (Carlotto e Palazzo, 2006; Contaifer e col., 2003; Jimenez e col., 2002; MorenoJiménez e col., 2000).

O surgimento dessa patologia entre os docentes afeta diretamente o ambiente escolar e irá interferir na obtenção dos objetivos pedagógicos. Pode ser percebida através de uma série de sintomas como a alienação, desumanização, apatia, insônia, gastrite, alterações menstruais, alergias, cefaleia, palpitações, hipertensão arterial, uso abusivos de medicamentos e álcool. Estes sintomas acabam por 
acarretar conflitos sociais e familiares e problemas de saúde, levando ao aumento do absenteísmo e à intenção de abandonar a carreira de docência (Carlotto e Palazzo, 2006; Farber, 1999).

Os estudos a respeito das variáveis que podem levar ao surgimento da Síndrome de Burnout as dividem em três: demográficas (sexo, idade, estado civil e ter filhos), laborais e fatores estressantes.

Dentre as variáveis demográficas, esses estudos demonstram que não há diferenças estatisticamente significativas entre sexo e estado civil (Carlotto e Palazzo, 2006; Mohammed, 1995; Maslach e Jackson, 1981). Em relação à idade e ter filhos, os professores mais jovens apresentam maiores níveis da Síndrome e os que possuem filhos, menores níveis (Carlotto e Palazzo, 2006; Codo, 1999; Byrne, 1991). Esses relatos demonstram que as variáveis demográficas não são as que possuem maior poder preditivo e de associação com Burnout (Carlotto e Palazzo, 2006; Silva e Carlotto, 2003; Smith e Goh, 2003; Maslach e col., 2001; Maslach e Leiter, 1997).

A literatura aponta, na interface entre as variáveis laborais e os fatores de estresse, uma forte relação entre a quantidade de tempo despendido em situações que impliquem nas relações interpessoais e altos níveis nas dimensões de Burnout (Carlotto e Palazzo, 2006; Benevides-Pereira, 2002; Malasch e Leiter, 1999). A demanda de alunos assistidos diariamente pelos professores (em média 100 alunos) tem associação significativa com a exaustão emocional (Carlotto e Palazzo, 2006; Jimenez e col., 2002; Pines e col., 2002; Cordes e Dougherty, 1993; Russel e col., 1987). Alguns trabalhos apontam a influência da formação profissional com a habilidade para enfrentar o estresse do trabalho, ou seja, profissionais mais capacitados estão menos sujeitos ao desgaste (Wagner, 2004; Jesus, 2002; Lautert, 1997).

A carga horária também indica ser um elemento associado à exaustão emocional. Como o ensino privado vem se expandindo, há um aumento no quantitativo de turmas, que pode resultar, entre os docentes, em um sentimento de esgotamento emocional. Essa demanda mental é apontada na literatura como um dos fatores estressores de maior impacto sobre a saúde dos professores (Carlotto e Palazzo, 2006; Benevides-Pereira, 2002; Carlotto, 2002b; Lee e Ashforth, 1993; Maslach, 1976). Está relacionada também às atividades em classe onde haja problemas de disciplina e de motivação, principalmente ao lidar com grupos heterogêneos (Diniz e Guimarães, 2004; Ben-Ari e col., 2003).

É importante salientar que o profissional, ao dispor de tempo para o lazer, torna-se menos vulnerável ao Burnout (Carlotto, 2002b). Porém, SeligmannSilva (1986) alerta para o fato de que normalmente os profissionais utilizam seu tempo de não trabalho para o descanso e isto não significa lazer. O lazer promove uma sensação de satisfação e bem-estar e propicia descanso e divertimento, além de agir como fator positivo para o desenvolvimento pessoal e social de cada indivíduo (Madsen, 2002).

No entanto, de acordo com Vieira (2003), é preciso considerar as possibilidades dos professores tanto de tempo livre, quanto de poder aquisitivo. Muitos docentes ganham pouco e muitas atividades de lazer terminam por serem preteridas ou adiadas. Em relação ao tempo, suas jornadas de trabalho são intensas e exaustivas, muitas vezes incluindo os sábados.

Estudos identificam as causas do surgimento da Síndrome de Burnout em professores, não a partir do indivíduo (professor), mas a partir de fatores localizados no ambiente social laboral. Esses fatores estão em três níveis: micro, meso e macrossociais (Carlotto e Palazzo, 2006; Woods, 1999; Maslach e Leiter, 1997). Os fatores microssociais seriam aqueles situados dentro da atividade profissional, ou seja, comprometimento, relacionamentos profissionais, fatores de interação com os alunos e na relação com os pais pelas expectativas ao seu trabalho de docência. Os fatores intermediários envolvem as políticas institucionais, aspectos éticos, aspectos culturais do professor e dos alunos, e os macrossociais seriam todas as forças derivadas das tendências globais e políticas governamentais, podendo ser entendidos, de acordo com Carlotto e Palazzo (2006), como um novo paradigma estabelecido a partir da concepção de escola como empresa enquanto prestadora de serviços.

As escolas possuem a meta de desenvolver habilidades individuais e sociais que auxiliem os alunos na construção de suas vidas e na contribuição para a vida de outros com os quais se relacionam (WHO, 1996). Como espaços sociais e de convívio, oportuniza ações de promoção de saúde de todos os membros 
de sua comunidade: professores, funcionários e familiares, além dos próprios estudantes. Para tanto, necessitam ser um espaço saudável.

O conceito de ambientes saudáveis incorpora vários fatores, dentre os quais estão os ambientes físicos relacionados à infraestrutura predial, indo até os que se relacionam à saúde, como os psicossociais. Ambiente e saúde são interdependentes e inseparáveis (OPAS, 1998). Assim, há a necessidade do estabelecimento de programas multi e interdisciplinares que incentivem a construção de ambientes saudáveis, para que se constituam em ferramenta para otimização dos resultados em um processo gradativo de melhoria da qualidade de vida (Cohen e col., 2007).

\section{Considerações Finais}

Pretendeu-se neste trabalho proporcionar, de forma objetiva e estruturante, uma familiarização com os principais fatores de riscos para o desenvolvimento da Síndrome de Burnout em docentes.

0 desgaste emocional a que os docentes estão sujeitos nas relações com o trabalho são fatores muito significativos na determinação dos transtornos relacionados ao estresse, como é o caso da Síndrome de Burnout.

É necessário o aprofundamento de pesquisas sobre a manifestação do estresse ocupacional entre os docentes, a fim de auxiliar na compreensão e na elucidação de alguns problemas enfrentados por essa atividade, como a insatisfação profissional, o baixo rendimento no trabalho, o absenteísmo e algumas doenças ocupacionais, dentre elas o Burnout. Melhorando a compreensão desses processos, haverá condições de planejar e implementar ações intervencionistas e preventivas nos locais de trabalho em busca de soluções adequadas. Essas contribuições, especialmente no que se refere à organização do trabalho e seu papel estruturador, podem subsidiar a adoção de estratégias preventivas, visando também a saúde mental dos trabalhadores e a constituição do ambiente laboral escolar saudável.

A revisão de literatura feita neste trabalho demonstra a carência de pesquisas nessa área. Os estudos encontrados são predominantemente descritivos, não havendo estudos sobre programas de prevenção e de intervenção para cuidar do estresse do professor.

Observou-se que aspectos históricos da construção da profissão docente são diferenciados no contexto brasileiro. Há uma dicotomia social, cultural e econômica relativas a essa profissão. Professores universitários possuem uma representação social de maior status que professores de escolas.

Além disso, mesmo dentro de uma mesma categoria profissional, existem indivíduos que se apresentam marcadamente diferentes. Esta especificidade, que envolve diversos fatores, inclusive o histórico de vida; constitui-se uma dificuldade para a apreensão do nexo entre adoecimento mental e situação de trabalho.

É necessário, portanto, o desenvolvimento de estudos interdisciplinares que possibilitem compreender a dimensão psicossocial do trabalho e sua relação com o processo e ambiente da atividade de labor, a inserção ocupacional e o processo saúdedoença mental, para que possibilitem novas alternativas metodológicas no patamar da investigação e da intervenção nas organizações, promovendo espaços saudáveis e sustentáveis.

\section{Referências}

ARAÚJO, T. M. et al. Mal-estar docente: avaliação de condições de trabalho e saúde em instituições de ensino superior. Revista Baiana de Saúde Pública, Salvador, v. 29, n. 1, p. 6-21, jan./jun. 2005.

BEN-ARI, R.; KROLE, R.; HAR-EVEN, D.

Differential effects of simple frontal versus complex teaching strategy on teacher stress, burnout and satisfaction. International Journal of Stress Management, New York, v. 10, n. 2, p. 173195, May 2003.

BENEVIDES-PEREIRA, A. M. T. Burnout: o processo de adoecer pelo trabalho. In: BENEVIDES-PEREIRA, A. M. T. (Org.). Burnout: quando o trabalho ameaça o bem-estar do trabalhador. São Paulo: Casa do Psicólogo, 2002. p. 21-91. 
BRANDÃO JUNIOR, P. S. Biossegurança e AIDS: dimensões psicossociais do acidente com material biológico no trabalho hospitalar. In: VALLE, S.; TELLES, J. L. (Orgs.). Bioética e biorrisco: abordagem transdisciplinar. Rio de Janeiro: Interciência, 2003. p. 217-228.

BRASIL. Ministério da Saúde. Doenças relacionadas com o trabalho: diagnósticos e condutas - manual de procedimentos para os serviços de saúde. Brasília, DF, 2002.

BRASIL. Ministério da Saúde. Portaria n. 1339/ GM, de 18 de novembro de 1999. Institui a lista de doenças relacionadas ao trabalho e dá outras providências. Diário Oficial da União, Brasília, DF, 19 nov. 1999, Seção I, p. 21.

BURKE, R. J.; GREENGLASS, E. R.; SCHWARZER, R. Predicting teacher burnout over time: effects of work stress, social support and self-doubts on burnout and its consequences. Anxiety, Stress and Coping, London, v. 9, n. 3, p. 261-275, 1996.

BYRNE, B. M. Burnout: investigating the impact of background variables for elementary, intermediate, secondary, and university educators. Teaching and Teacher Education, New York, v. 7, n. 2, p. 197-209, 1991.

CARLOTTO, M. S. A síndrome de Burnout e o trabalho docente. Psicologia em estudo, Maringá, v. 7, n. 1, p. 21-29, jan./jun. 2002a.

CARLOTTO, M. S. Síndrome de Burnout e satisfação no trabalho: um estudo com professores universitários. In: BENEVIDES-PEREIRA, A. M. T. (Org.). Burnout: quando o trabalho ameaça o bem-estar do trabalhador. São Paulo: Casa do Psicólogo; 2002b. p. 187-212.

CARLOTTO, M. S.; PALAZZO, L. S. Síndrome de Burnout e fatores associados: um estudo epidemiológico com professores. Cadernos de Saúde Pública, Rio de Janeiro, v. 22, n. 5, p. 10171026, maio 2006.

CASTRO, F. G.; ZANELLI, J. C. Sindrome de Burnout e projeto de ser. Cadernos de Psicologia Social do Trabalho, São Paulo, v. 10, n. 2, p. 17-33, dez. 2007.
CODO, W. Educação: carinho e trabalho.

Petrópolis: Editora Vozes, 1999.

CODO, W.; VASQUES, I. M. Trabalho docente e sofrimento: burnout em professores. In: AZEVEDO, J.; GENTILI, P.; KRUG, A.; SIMON, C. (Orgs). Utopia e democracia na educação cidadã. Porto Alegre: Editora Universidade, 200oa. p. 369381.

CODO, W.; VASQUES, I. M. Burnout: sofrimento psíquico dos trabalhadores em educação.

Cadernos de Saúde do Trabalhador, Brasilia: CUT, 2ooob. 53p.

COHEN, S. C. et al. Habitação saudável e ambientes favoráveis à saúde como estratégia de promoção da saúde. Ciência e Saúde Coletiva, Rio de Janeiro, v. 12, n. 1, p. 191-198, mar. 2007.

CONTAIFER, T. R. C. et al. Estresse em professores universitários da área de saúde. Revista Gaúcha de Enfermagem, Porto Alegre, v. 24, n. 2, p. 215-225, ago. 2003.

CORDES, C. L.; DOUGHERTY, T. W. A review and integration of research on job burnout. Academy of Management Review, New York, v. 18, p. 632636, 1993 .

COSTA, J. R. A.; LIMA, J. V.; ALMEIDA, P. C. Stress no trabalho do enfermeiro. Revista da Escola de Enfermagem da USP, São Paulo, v. 37, n. 3, p. 63-71, set. 2003 .

CRANE, S. J.; IWANICKI, E. F. Perceived role conflict, role ambiguity, and burnout among special education teachers. Remedial and Special Education, London, v. 7, p. 24-31, Mar./Apr. 1986.

DEJOURS, C. A loucura do trabalho. São Paulo: Cortez-Oboré, 1992.

DIAS, E. C. A organização da atenção à saúde no trabalho. In: FERREIRA JUNIOR, M. Saúde no trabalho: temas básicos para o profissional que cuida da saúde dos trabalhadores. São Paulo: Ed. Roca, 200o. p. 3-27.

DINIZ, R. L.; GUIMARÃES, L. B. M. Avaliação da carga de trabalho mental. In: GUIMARÃES, L. B. M. Ergonomia cognitiva. Porto Alegre: Feeng, 2004. p. 43-57. 
DOMÉNECH, B. D. Introduccion al sindrome "burnout" en profesores y maestros y su abordaje terapeutico. Psicologia Educativa, Madrid, v. 1, n. 1, p. 63-78, 1995 .

FARBER, B. A. inconsequentiality - the key to understanding teacher burnout. In: VANDERBERGUE, R.; HUBERMAN, M. A. (Eds.). Understanding and preventing teacher burnout: a source book of international practice and research. Cambridge: Cambridge University Press, 1999. p. 159-165.

FERENHOF, I. A.; FERENHOF, E. A.síndrome de Burnout em professores. Eccos - Revista Científica, São Paulo, v. 4, n. 1., p. 131-151, jun. 2002.

FERNANDES, S. Transformações no mundo do trabalho e a saúde psíquica: a ótica do estresse ocupacional. Organizações \& Sociedade, Salvador, v. 6, n. 16, p. 67-75, 1999.

FRANÇA, A. C. L.; RODRIGUEZ, A. L. Stress e trabalho. São Paulo: Atlas, 1999.

FRANÇA, A. C. L.; RODRIGUES, A. L. Stress e trabalho: guia básico com abordagem psicossomática. São Paulo: Altas, 1997. 133 p.

FRANÇA, H. H. A Síndrome de "Burnout". Revista Brasileira de Medicina, São Paulo, v. 44, n. 8, p. 197-199, 1987.

FRANCO, T. Trabalho alienado: habitus \& danos à saúde humana e ambientais (o trabalho entre o céu, a terra e a história). Tese. (Doutorado em Ciências Sociais). Instituto de Ciências Sociais, Universidade Federal da Bahia, Salvador, 2003.

FREUDENBERG, H. J. Staff Burn-out. Journal of Social Issues, Malden, v. 30, n. 1, p. 159-165, 1974.

FRIEDMAN, I. A. High-and low-burnout schools: school culture aspects of teacher burnout. Journal of Educational Research, Washington, v. 84, n. 6, p. 325-333, 1991.

FRIEDMAN, I. A. Measuring school principal experienced burnout. Educational and Psychological Measurement, Durham, v. 55, n. 4, p. 641-651, 1995.
FRIEDMANN, G. O trabalho em migalhas. São Paulo: Perspectiva, 1983.

FRIGOTTO, G. Educação e Formação Humana: ajuste neoconservador e alternativa democrática. In: GENTILI, P. A. A.; SILVA, T. T. (Orgs.).

Neoliberalismo, qualidade total e educação: visões críticas. Petrópolis: Vozes, 1999. p. 31-92.

GLINA, D. M. R. et al. Saúde mental e trabalho: uma reflexão sobre o nexo com trabalho e o diagnóstico, com base na prática. Cadernos de Saúde Pública, Rio de Janeiro, v. 1, n. 3, p. 607-616, maio/jun. 2001.

JESUS, S. N. Prevenção do mal-estar docente através da formação de professores. Revista Educação, Porto Alegre, v. 25, n. 48, p. 25-43, 2002.

JIMENEZ, B. M. et al. A Avaliação do Burnout em Professores. Comparação de Instrumentos: CBP-R e MBI-ED. Psicologia em Estudo, Maringá, v. 7, n. 1, p. 11-19, jan./jun. 2002.

LAUTERT, L. O desgaste profissional: uma revisão da literatura e implicações para a enfermeira. Revista Gaúcha de Enfermagem, Porto Alegre, v. 18, n. 2, p. 133-144, 1997.

LEE, R. T.; ASHFORTH, B. E. A further examination of managerial burnout: toward an integrated model. Journal of Organizational Behavior, Hoboken, v. 14, n. 1, p. 3-20, 1993.

LEITER, P. M.; MASLACH, C. The impact of interpersonal environment on burnout and organizational commitment. Journal of Organizational Behavior, v. 9, n. 4, p. 297-308, 1988.

LIPP, M. E. N. O stress está dentro de você. São Paulo: Contexto, 2000.

LIPP, M. E. N. Pesquisas sobre stress no Brasil: saúde, ocupações e grupos de risco. 2. ed. Campinas, SP: Papirus, 2001.

LIPP, M. E. N. Stress no trabalho: implicações para a pessoa e para a empresa. In: NUNES SOBRINHO, F. P.; NASSARALLA, I. (Eds.). Pedagogia

Institucional - fatores humanos nas organizações. Rio de Janeiro: ZIT Editores, 2004. p. 214-236. 
LIPP, M. E. N.; ROCHA, J. C. Pressão alta e stress: o que fazer agora? Campinas: Papirus, 2008.

MADSEN, J. E. H. Lazer na empresa e lazer pela empresa: a associação da marca da empresa ao lazer e qualidade de vida. In: MARCELINO, N. C. (Org.) Lazer e empresa: alguns múltiplos olhares possíveis. 3. ed. Campinas: Papirus, 2002. p. 95-111.

MANASSERO, M. A. et al. Burnout en la enseñanza: análisis de sus incidencias y factores determinantes. Revista de Educación, Madrid, v. 1, n. 306, p. 241-266, 1995 .

MASLACH, C. Burnout: a multidimensional perspective. In: SCHAUFELI, W. B.; MASLACH, C.; MAREK, T. (Eds.). Professional Burnout: recent developments in theory and research. New York: Taylor \& Francis, 1993. p. 19-32.

MASLACH, C. Burned-out. Human Behavior, New Jersey, v. 5, n. 9, p. 16-22, 1976.

MASLACH, C.; JACKSON, S. E. The measurement of experienced burnout. Journal of Occupational Behavior, Sussex, England, v. 2, n. 2, p. 99-113, 1981.

MASLACH, C.; LEITER, M. P. The truth about burnout: how organization cause, personal stress and what to do about it. San Francisco: JosseyBass, 1997.

MASLACH, C.; LEITER, M. P. Take this job and love it. Psychology Today, New York, v. 32, n. 1, p. 50-57, 1999.

MASLACH, C.; SCHAUFELI, W. B.; LEITER, M. P. Job burnout. Annual Review of Psychology, Palo Alto, v. 52, n. 1, p. 397-422, 2001.

MASLACH, C.; LEITER, M. P. Revertendo o Burnout: como reacender sua paixão pelo trabalho. In: CONGRESSO DE STRESS DA ISMABR, 8.; FÓRUM INTERNACIONAL DE QUALIDADE DE VIDA NO TRABALHO, 10., 2008, Porto Alegre. Anais... Porto Alegre: ISMA, 2008. CD Rom.

MENDES, R. Patologias do trabalho. Rio de Janeiro: Atheneu, 1995. 643p.

MOHAMMED, A. A. The effect of some personality traits, sex, and experience on teacher burnout.

Derasat Nafseyah, Cairo, v. 5, n. 2, p. 345-376, 1995.
MORENO-JIMÉNEZ, B. Olvido y recuperación de los factores psicosociais en la salud laboral. Archivos de Prevención de Riesgos Laborales, Madrid, v. 3, n. 1, p. 3-4, jan./mar. 2000.

MORENO-JIMÉNEZ, B.; HERNÁNDEZ, E. G.; GUTIÉRREZ, G. J. L. La evaluación del estrés y el burnout del profesorado: el CBP-R. Revista de Psicología del Trabajo y de las Organizaciones, Madrid, v. 16,n. 2, p. 151-171, 2000.

MURPHY, L. Occupational stress management: a review and appraisal. Journal of Occupational Psychology, Leicester, v. 57, p. 1-15, 1984.

PAFARO, R. C.; MARTINO, M. M. F. Estudo do estresse do enfermeiro com dupla jornada de trabalho em um hospital de oncologia pediátrica de Campinas. Revista da Escola de Enfermagem da USP, São Paulo, v. 38, n. 2, p. 152-16o, 2004.

SILVA, F. P. P. Burnout: um desafio à saúde do trabalhador. Revista de Psicologia Social e Institucional, Londrina, v. 2, n. 1, p. 82-109, 2000. Disponível em: http://www2.uel.br/ccb/psicologia/ revista/textov2n15.htm. Acesso em: 10 dez. 2009.

PINES, A. M. et al. A cross-cultural investigation of social support and burnout. European Psychologist American Psychologial Association, Basel, v. 7, n. 4, p. 256-264, 2002.

RODRIGUES, A. L.; GASPARINI, A. C. L. F. Uma perspectiva psicossocial em psicossomática: via estresse e trabalho. In: MELLO FILHO, J. Psicossomática hoje. Porto Alegre: Artes Médicas, 1992. p 93-107.

RUDOW, B. Stress and burnout in the teaching profession: european studies, issues, and research perspectives. In: VANDERBERGUE, R.; HUBERMAN, M. A. (Eds.). Understanding and preventing teacher burnout: a source book of international practice and research. Cambridge: Cambridge University Press, 1999. p. 38-58.

RUSSEL, D. W.; ALTMAIER, E.; VAN VELZEN, D. Job-related stress, social support, and burnout among classroom teachers. Journal of Applied Psychology, Washington, v. 72, n. 2, p. 269-274, 1987. 
SCHAUFELI, W. Evaluación de riesgos psicosociales y prevención del estrés laboral: algunas experiencias holandesas. Revista de Psicologia del Trabajo y de las Organizaciones, Madrid, v. 15, n. 2, p. 147-171, 1999.

SCHAUFELI, W. B.; MASLACH, C.; MAREK, T. The future of burnout. In: SCHAUFELI, W. B; MASLACH, C.; MAREK, T. (Orgs.) Professional burnout, recent developments in theory and research. Philadelphia: Taylor \& Francis, 1993. p. 253-259.

SELIGMANN-SILVA, E. Crise econômica, trabalho e saúde mental. In: ANGERAMI-CAMON, V. (Org.)

Crise, trabalho e saúde mental no Brasil. São

Paulo Traço Editora, 1986. p. 54-132.

SELYE, H. Stress a tensão da vida. 2. ed. São Paulo: Ibrasa, 1965.

SILVA, G. N.; CARLOTTO, M. S. Síndrome de Burnout: um estudo com professores da rede pública. Psicologia Escolar e Educacional, Campinas, v. 7, n. 2, p. 145-153, 2003.

SMITH, D.; GOH, W. L. Prevalence and sources of burnout in Singapore secondary school physical education teachers. Journal of Teaching in Physical Education, Champaign, v. 22, n. 2, p. 203218, 2003.
SOUSA, A. F. Estresse ocupacional em motoristas de ônibus urbano: o papel das estratégias de coping. 2005. 176 p. Dissertação (Mestrado em Filosofia) - Faculdade de Filosofia e Ciências Humanas da Universidade Federal da Bahia, Salvador.

STRAUB, R. O. Enfrentando o estresse. Porto Alegre: Artmed, 2005.

VIEIRA, J. D. Identidade expropriada: retrato do educador brasileiro. Brasília: CTNE, 2003.

WAGNER, D. F. Síndrome de Burnout: um estudo junto aos educadores (professores e educadores assistentes) em escolas de educação infantil. 2004. 113 p. Dissertação (Mestrado em Engenharia de Produção) - Escola de Engenharia da Universidade Federal do Rio Grande do Sul, Porto Alegre.

WOODS, P. Intensification and stress in teaching. In: VANDERBERGUE, R.; HUBERMAN, M. A. (Eds.). Understanding and preventing teacher burnout: a source book of international practice and research. Cambridge: Cambridge University Press, 1999. p. 115-138.

OPAS - PAN AMERICAN HEALTH ORGANIZATION. Health in the Americas, Washington, DC, v. 1, 1998 (Scientific Publication $n^{\circ}$ 569, 1998. 359 p.).

WHO - WORLD HEALTH ORGGANIZATION. Western Pacific Regional Office. Report. Xangai, 1996 (WHO - Technical Report Series, 4, 38 p.). 